\title{
SYNOVIAL CHONDROMATOSIS OF THE KNEE IN CHILDHOOD
}

\author{
A REPORT OF TWO CASES
}

R. P. L. CAREY

\author{
From the Royal Children's Hospital, Melbourne
}

\begin{abstract}
Synovial chondromatosis is a rare metaplastic condition affecting major synovial joints. It is extremely rare in childhood. The two children reported here are believed to be the youngest patients with this condition affecting the knee to have been described in the literature.
\end{abstract}

Synovial chondromatosis is a rare condition characterised by the formation of chondro-osseous bodies in the synovium and subsynovial connective tissue of affected structures, usually major synovial joints (Lichtenstein 1977). The knee is the most commonly affected joint. The condition is invariably monarticular, and affects adults in their third, fourth and fifth decades (Jeffreys 1967).

The aetiology of this condition is unknown, but the pathogenesis has been well described (Aegerter and Kirkpatrick 1975; Lichtenstein 1977; Dahlin 1978). Loose bodies are the end-result of a metaplastic error of synovial cells. Microscopic masses of chondroid begin to appear, usually in the tips of synovial villi. The surrounding cells alter to resemble chondroblasts. These cartilage aggregations grow, producing spherical bodies with the villi as their pedicles. Eventually they may detach to become free bodies in the joint space, the cellular elements in these loose bodies being nourished by synovial fluid so that they can continue to grow. Cellular metaplasia may occur with the appearance of osteoblasts and a bony nidus may form. Hundreds of loose bodies may occur in this manner (Aegerter and Kirkpatrick 1975).

On review of the literature, it seems that the two cases presented here are considerably younger than any previously reported involving the knee.

\section{CASE REPORTS}

Case 1. A 10-year-old boy presented to the Royal Children's Hospital, Melbourne, in March 1980 with a four-month history of episodic mild swelling of the left knee, noted particularly after exercise. There was no history of trauma and no other joints were, or had been,

R. P. L. Carey, FRACS, Commonwealth Orthopaedic Registrar Princess Margaret Rose Orthopaedic Hospital, Fairmilehead, Edinburgh EHIO 7ED, Scotland.

Requests for reprints should be sent to Mr M. B. Menelaus, FRACS, Chief Orthopaedic Surgeon, Department of Orthopaedic Surgery, Royal Children`s Hospital, Flemington Road, Parkville, Victoria 3052, Australia.

(C) 1983 British Editorial Society of Bone and Joint Surgery 0301-620X/83/4094\$2.00 affected. The family history, his own past history and his general health were unremarkable.

Clinical examination. The boy had a normal gait, but was unable to squat due to discomfort in the left knee. The left knee was moderately swollen with mild tenderness

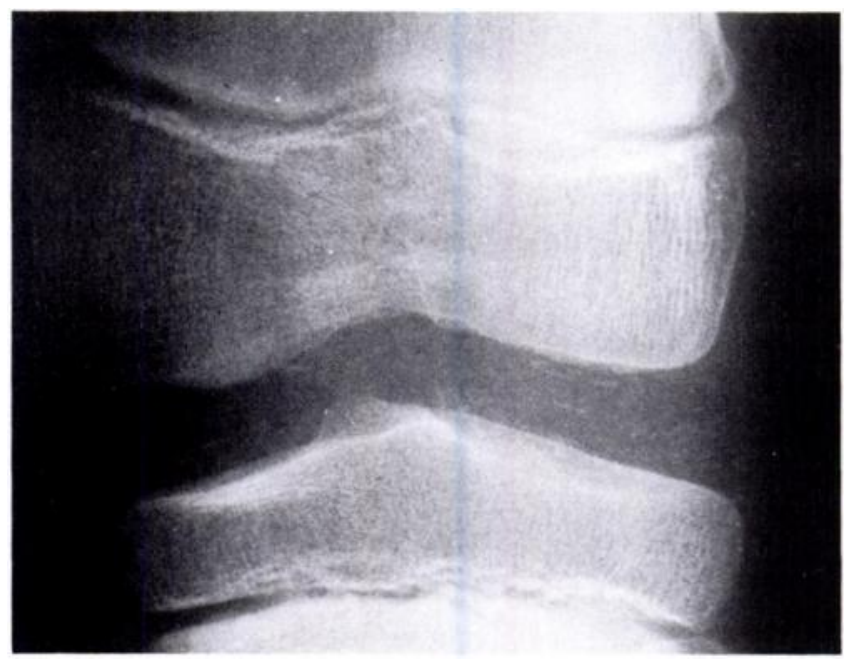

Fig. 1

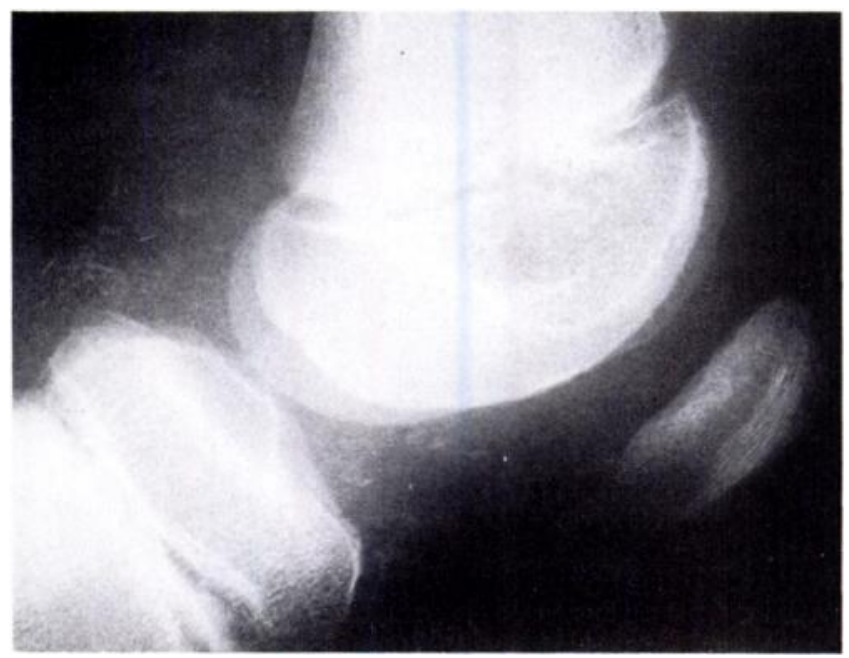

Fig. 2

Case 1. Figure 1-Anteroposterior radiograph of the left knee before operation. Figure 2-Lateral radiograph. 
all over the anterior aspect. There was mild patellofemoral discomfort on direct pressure. The range of movement was from full extension to 90 degrees of flexion. The knee was stable. One centimetre of wasting of the left quadriceps was evident. All other joints were normal, as was the general physical examination. Slitlamp examination of the eyes was normal.

Haematologicai investigations. The erythrocyte sedimentation rate (five millimetres in the first hour) and the serum chemistry, including the levels of calcium, phosphate and alkaline phosphatase, were normal. Antinuclear factor and rheumatoid factor were not detected. Radiographic examination. Radiographs showed faint stippled intra-articular calcification in the left knee which was not confined to the articular or meniscal cartilages (Figs 1 and 2). Some specks were evident in the patellofemoral joint space on the lateral radiograph (Fig. 2). There was no ligamentous calcification and the growth plates were normal.

A provisional diagnosis of synovial chondromatosis was made, and the patient admitted to hospital for arthrotomy.

Operation. In a bloodless field, a lateral parapatellar incision was made. When the synovial membrane was opened, straw-coloured fluid exuded in large amounts, containing hundreds of cartilaginous loose bodies in the form of small flakes two to four millimetres in diameter. Many more were attached to the synovial membrane. A

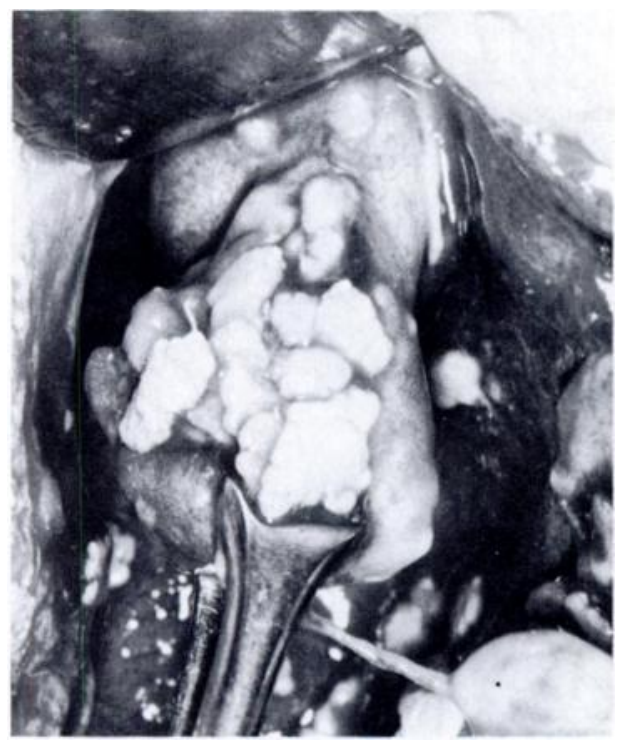

Fig. 3

Case 1. Macroscopic appearance of synovial chondromatosis at arthrotomy.

large pedunculated mass (Fig. 3) arose from the suprapatellar pouch, and this, along with further pieces of synovium, were excised and sent for histopathological examination. The joint was washed out with normal saline to remove all loose bodies. No attempt was made to undertake synovectomy, either limited or total. The wound was closed in layers. The patient recovered well and was discharged three days after operation. Macroscopic and histological examination of specimens removed at operation confirmed the diagnosis of synovial chondromatosis.

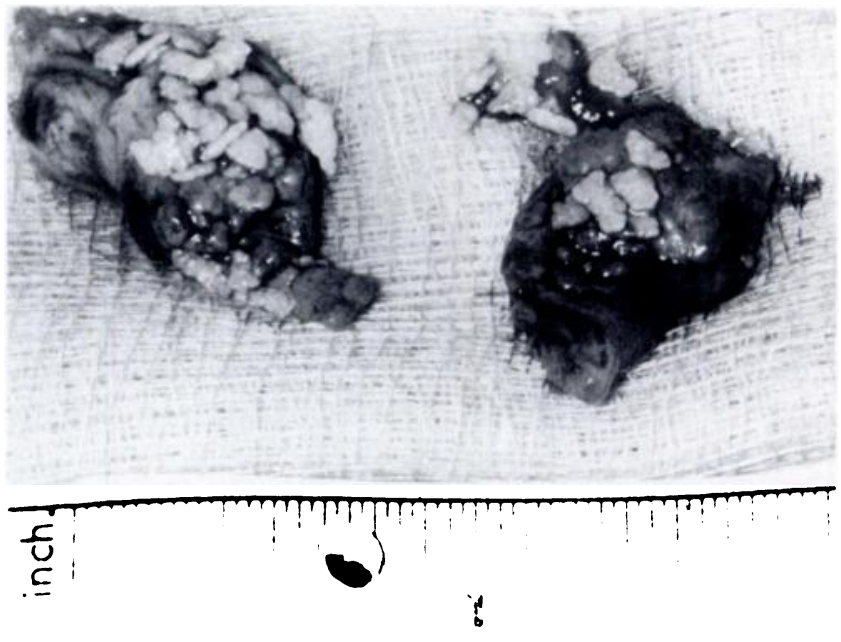

Fig. 4

Case 1. Macroscopic specimens showing subsynovial and adherent extra-synovial chondro-osseous bodies.

Review of the patient more than two years postoperatively revealed a clinically near-normal knee; there was full activity with no pain and the range of movement was from full extension to 10 degrees short of full flexion. The radiographic appearances, however, were unchanged.

Case 2. A nine-year-old girl was first seen in October 1981 with a 12-month history of recurrent swelling with discomfort in the left knee. There was no history of trauma or intercurrent infection. There had been increasing nocturnal discomfort in the eight weeks before initial consultation.

Clinical examination. The girl had a mild swelling of the knee without evidence of inflammation. There was minimal anterior tenderness which was not confined to any particular structure. There was two centimetres of wasting of the left quadriceps. The range of movement was from full extension to 30 degrees short of full flexion. During flexion, mobile nodules were palpable over the lateral joint space.

Haematological investigations. The erythrocyte sedimentation rate (14 millimetres in the first hour) and the serum chemistry were normal; haemagglutination test for rheumatoid arthritis was weakly positive.

Radiographic examination. Radiographs showed identical findings to those of Case 1.

A provisional diagnosis of synovial chondromatosis was made, the patient was admitted to hospital, and diagnostic arthroscopy was undertaken. Macroscopic appearances were consistent with synovial chondromatosis and arthroscopic biopsy confirmed this.

Three weeks later, a limited synovectomy was undertaken, extensive areas of thickened synovium being excised and sent for histological examination. 
When the girl was reviewed two months after operation her knee was comfortable and had healed well. Walking and general activities were painless and flexion was greater than 90 degrees. Regular review is now in progress.

\section{PATHOLOGY}

Both cases presented identical macroscopic (Fig. 4) and histological findings. Microscopically, the synovial lining was seen to be thickened, with lining cells being both hypertrophic and hyperplastic. Studded throughout the hyperplastic subsynovial layer of connective tissue were foci of hyaline cartilage, many of which were in the process of ossifying, or had undergone ossification (Figs 5,6 and 7). The diagnosis of synovial chondromatosis in each case was thus beyond doubt.

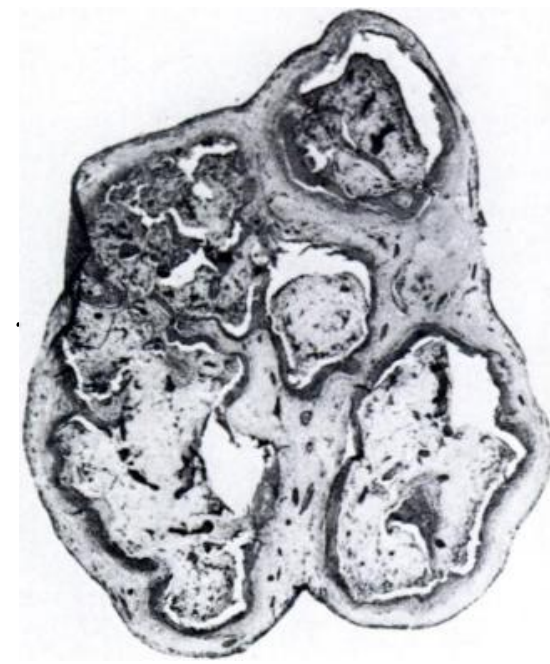

Fig. 5
Milgram reported 30 cases in 1977 , the youngest being 17 , but the youngest involving the knee was aged 19 . Jeffreys (1967) reported this condition in a 14-year-old patient, but the site was not noted. Four case reports from Cahuzac et al. (1979) in the French literature involved children as young as two years, but none involved the knee.

Although Murphy et al. (1962) take an opposing view, the tendency for this condition to remain indolent or to resolve spontaneously after simple arthrotomy, after lavage to remove loose bodies or after subtotal synovectomy, or indeed without any intervention at all, seems generally accepted (Freund 1937; Mussey and Henderson 1949; Jeffreys 1967; Milgram 1977; Cahuzac et al. 1979). Only one documented case of apparent progression to chondrosarcoma has been reported, the transition occur-

Figure 5. Case 1-Cross section through the pedunculated mass seen in Figure 3. Circumscribed chondro-osseous bodies are seen in the subsynovial connective tissue (haematoxylin and eosin, $\times 5$ ). Figure 6. Case 2 -Low power view of pedunculated mass with chondro-osseous material (haematoxylin and eosin. $\times 10$ ). Figure 7-High power view of Figure 6, showing chondroid tissue and osteoid tissue with multinucleated osteoclastic giant cells and Howship's lacunae (haematoxylin and eosin, $\times 25$ ).

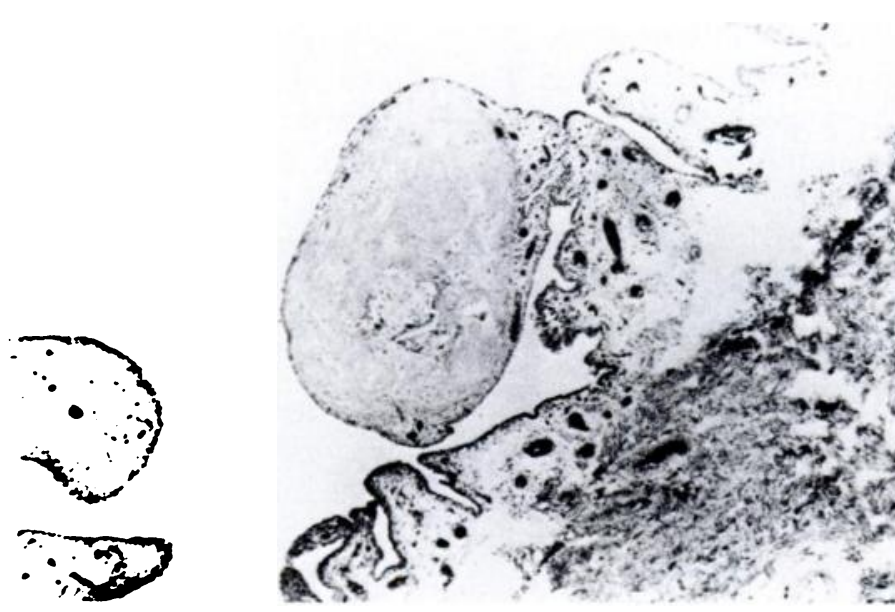

Fig. 6

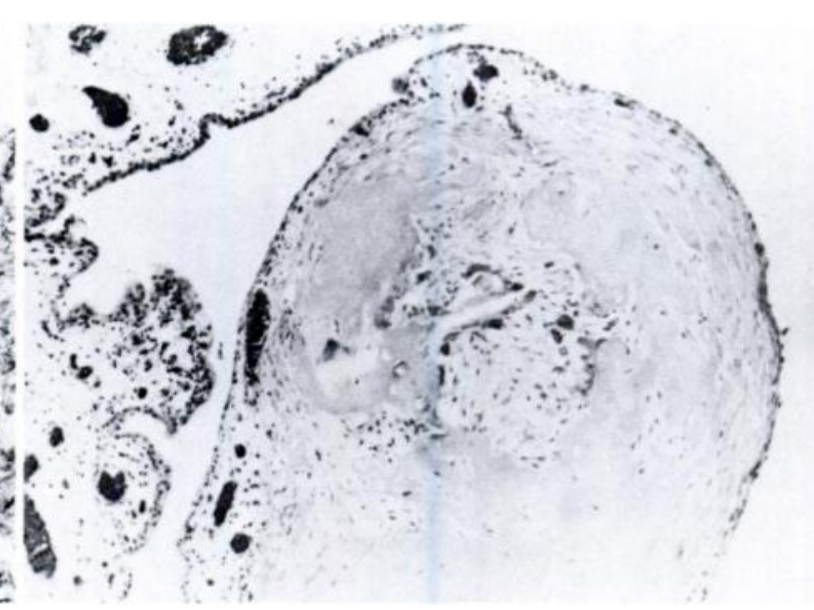

Fig. 7
DISCUSSION

On review of the literature, it seems that these cases are considerably younger than any previously reported involving the knee. Murphy, Dahlin and Sullivan (1962) reported a case in a 16-year-old patient, Mussey and Henderson (1949) in a child of 13 years, and Coventry, Harrison and Martin (1966) reported a patient aged 14. ring in a woman over a period of 14 years (Mullins, Berard and Eisenberg 1965).

The follow-up of Case 1 more than two years after operation would seem to confirm the indolent nature of this condition in childhood. The technical difficulties, not to mention the undesirability, of "total" synovectomy of the knee in children are emphasised. 


\section{ACKNOWLEDGEMENTS}

The author is most grateful to Mr M. B. Menelaus (Melbourne, Australia) and Mr A. Hodgkinson (Sydney, Australia) for permission to publish details of their cases, and to Dr P. Campbell (Melbourne, Australia) and Dr D. Painter (Sydney, Australia) for their expert histopathological interpretation of the operative specimens.

\section{REFERENCES}

Aegerter E, Kirkpatrick JA Jr. Orthopedic diseases: physiology, pathology, radiology. 4th ed. Philadelphia, London and Toronto: WB Saunders, 1975: 623-86.

Cahuzac JP, Lebarbier P, Germaneau J, Pasquié M. La chondromatose synoviale de l'enfant (à propos de 4 observations). Chir Pediatr $1979 ; 20: 89-93$.

Coventry MB, Harrison EG Jr, Martin JF. Benign synovial tumors of the knee: a diagnostic problem. J Bone Joint Surg [Am] 1966;48-A $1350-8$.

Dahlin DC. Bone tumours: general aspects and data on 6,221 cases. 3rd ed. Springfield: Charles C. Thomas, 1978: 405.

Freund E. Chondromatosis of the joints. Arch Surg 1937;34:670-86.

Jeffreys TE. Synovial chondromatosis. J Bone Joint Surg [Br] 1967;49-B:530-4.

Lichtenstein L. Tumors of synovial joints, bursae, and tendon sheaths. In: Lichtenstein L, ed. Bone tumors. 5th ed. St Louis: CV Mosby, 1977: $428-52$.

Milgram JW. Synovial osteochondromatosis. J Bone Joint Surg [Am] 1977;59-A:792-801.

Mullins F, Berard CW, Eisenberg SH. Chondrosarcoma following synovial chondromatosis. Cancer 1965; 18:1180-8.

Murphy FP, Dahlin DC, Sullivan CR. Articular synovial chondromatosis. J Bone Joint Surg [ Am] 1962;44-A :77-86.

Mussey RD Jr, Henderson MS. Osteochondromatosis. J Bone Joint Surg [ Am] 1949;31-A :619-27. 